\title{
Social support and quality of life among female breast cancer patients at Tikur Anbessa Specialized Hospital, Ethiopia 2019:Cross-sectional study
}

\author{
Rahel Aberaraw \\ Black Lion Hospital \\ Jemal Hussien \\ Jimma University \\ Abdisa Boka \\ Addis Ababa University \\ Roza Teshome \\ Addis Ababa University \\ Addisu Yeshambel ( $\nabla$ addisyes3@gmail.com ) \\ Wolaita Sodo University
}

Research

Keywords: Social support, Quality of life, Breast cancer

Posted Date: June 8th, 2020

DOI: https://doi.org/10.21203/rs.3.rs-33300/v1

License: (9) This work is licensed under a Creative Commons Attribution 4.0 International License.

Read Full License 


\section{Abstract}

Background Breast cancer is a major life-threatening public health problem worlwide. It is the most common form of cancer among women in many developing countries including Ethiopia. Social support could change the course of cancer and can influence the quality of life among breast cancer patients. Therefore, purpose of this study was to assess social support and quality of life among female breast cancer patients attending in Tikur Anbassa Specialized Hospital, Addis Ababa, Ethiopia 2019.

Methods A Hospital-based cross-sectional study was conducted in Tikur Anbessa Specialized Hospital, Ethiopia from March to April 2019. A total of 214 female breast cancer patients were included and a systematic sampling method was used. A structured and pre-tested questionnaire was used. Data entry was done using epi data manager version 4.2. Data analysis was done using Statistical Package for Social Sciences version 25. Binary and multiple logistic regression was used to show the association of social support and quality of life. Variables significantly associated were declared at P-value $<0.05$ and $95 \% \mathrm{Cl}$ was used.

Result A total of 214 women with breast cancer were recruited. Of the total participants, $124(58 \%)$ had good social support. It was found that participants who were college graduated (AOR=3, 95\%Cl: $1.5,5.9$ $\mathrm{COR}=3.2)$ and who had high monthly income(AOR=2.3, 95\% $\mathrm{Cl}: 1.2,8.5, \mathrm{COR}=5.39)$ were more likely to have good social support. It was also found that participants who were illiterate (AOR=3,95\%Cl: 1.3,6.9, $\mathrm{COR}=4.8$, $\mathrm{p}$-value=0.008), who had systematic therapy side effects $(\mathrm{AOR}=3.8,95 \% \mathrm{Cl}: 1.1,13, \mathrm{COR}=4$, $\mathrm{p}$ value $=0.035)$ and participants who had problem of appetite $\operatorname{loss}(\mathrm{AOR}=3.5,95 \% \mathrm{Cl}: 1.02,12 \mathrm{COR}=4$, $\mathrm{p}$-value= 0.047) were more likely to have affected QoL.

Conclusion In this study finding, social support and, quality of life in breast cancer patients was low. Healthcare providers should enhance social support which may help to improve the quality of life of women with breast cancer.

\section{Background}

Breast cancer is cancer originating from breast tissue, most commonly from the inner lining of milk ducts or the lobules that supply the ducts through milk. It is the most common cancer and the principal cause of cancer-related deaths in women worldwide(1). Different studies have shown that the number of patients with breast cancer is rising sharply in recent years. Its burden has become a major public health problem in developing regions (2).

In Ethiopia, around 60,000 new cases of breast cancer were diagnosed yearly (3). Reports indicated that breast cancer was the common cancer which accounts around $33 \%$ of all female cancer cases (4). Food insecurity and children withdrawal from school, increased work burden on children and loss of assets were the common problems following death of women with breast cancer during their most productive years (5). 
Perceived social support has been shown to be positively correlated with quality of life among breast cancer patients(6). Social support is a critical part of physical and mental health when fronting cancer care. However, it does not supernaturally appear and people are reluctant to request for help, even when they want it. Psychological research displays that people significantly underestimate the readiness of others to help(7). Preceding studies have initiated that good social support is associated with better survival(8) and a better quality of life after breast cancer. A recent meta-analysis combining data from 87 studies of social support and cancer consequences reported stronger inverse associations through cancer mortality among breast cancer survivors compared with other cancer sites(9).

In a study conducted in Tikur Anbessa specialized hospital, it accounts for $29.4 \%$ of cancer cases followed by cancer of the cervix $26.3 \%(10)$. Among cancer survivors, social support has been related to improved quality of life (11).

Study done on the association between social support and cancer survival stated having high levels of perceived social support and being married were connected with declines in risk ratios for mortality of $25 \%$ and $12 \%$, respectively (9) and other literature supposed that important relations of social support and quality of life outcomes for types of social support are significant mechanisms through which naturally occurring networks influence QOL outcomes after a breast cancer diagnosis(11).

Social-support can disturb how individuals access the health care system or health information(12) and can influence insights into normative health behaviors (13). The impact of social support and quality of life has not been well characterized on Ethiopian breast cancer patients. Therefore, this study was aimed to assess social support and quality of life among female breast cancer patients, in Addis Ababa, Ethiopia.

\section{Methods}

\section{Study Area and Setting}

The study was conducted at the Oncology center, TASH, Addis Ababa. It is the largest city in Ethiopia, with a population of $3,475,952$ according to the 2007 population census. Addis Ababa has 41 hospitals (13 public and 28 NGO and private), 29 health centers 122 health stations, 37 health posts and 382 modern private clinics (10).

Tikur Anbassa Specialized Hospital is a government-owned large referral teaching hospital, located in Kirkos sub-city under the administration of Addis Ababa University, College of Health sciences. The oncology center at the Hospital is the only referral center in the country (14).

\section{Study Design and Period}

A Hospital-based cross-sectional study was conducted from March1 to April 1/ 2019. 


\section{Source Population}

All breast cancer patients being evaluated and treated in oncology units

\section{Study population}

Those breast cancer patients visiting the hospital and being evaluated or treated at the oncology unit during data collection time

\section{Inclusion criteria}

All-female breast cancer patients who visited the hospital during the data collection period

\section{Exclusion criterion}

Serious ill patients, unwilling to fill the questionnaire and patients didn't take chemotherapy treatment were excluded.

\section{Sample size determination}

The sample size was calculated using a single proportion formula. By taking prevalence of breast cancer patients $14.8 \%$ (15), Marginal of error $=5 \%$ and $\mathrm{Cl}=95 \%$

$$
\begin{gathered}
\mathrm{n} \equiv(\underline{\mathrm{Z} \bigotimes / 2}) \cdot \underline{\underline{2}} \underline{\mathrm{p}}(\underline{1-} \mathrm{p})_{-}=(\underline{1.96}) \underline{2}(\underline{0.148})-(\underline{0.852})=194 \\
\mathrm{~d}^{2} \quad(0.05)^{2}
\end{gathered}
$$

by adding $10 \%$ non- response rate, the total sample size was 214

\section{Sampling procedure}

Tikur Anbessa Specialized Hospital was selected purposely because it is currently the only referral hospital for cancer patients in Ethiopia. Subjects were selected by using systematic random sampling by taking the one-year record of female breast cancer( 8000 cases), and taking average cases of one month(667 cases) from yearly report and the required sample size was taken every $\mathrm{K}^{\text {th }}$ value $=3$.

\section{Dependent variables}

Social support and Quality of life among female breast cancer patients. 


\section{Independent Variables}

Socio-demographic and economic variables (Age, educational status and religion, occupation and monthly income) , Clinical factors(Body mass index (BMI), stage of the diseases, time since diagnosis and type of treatment), and Lifestyle (smoking, alcohol intake and physical activity)

\section{Operational Definition}

Social support: defined as the degree to which interpersonal relationships serve particular support or functions (including emotional/informational support, tangible support, positive social interaction, and affectionate support (16).

Good social support: Participants who were scored mean and above the mean for social support questions.

Poor social support: Participants who were scored below the mean for social support questions.

Quality of life: Assessed by using functional scales, symptom scales, and global health status scales(17). The functional scale includes:-Physical, Role, Cognitive, Emotional, Social Functioning, body image, sexual functioning, sexual enjoyment, and future perspective. Global health status assessed by two items. And symptom scales include - fatigue, nausea and vomiting, pain, dyspnea, insomnia, appetite loss, constipation, diarrhea, financial difficulty, systemic therapy side effects, breast symptoms, arm symptoms and upset by hair loss.

Not affected quality of life: Participants who were scored 75 and above for functional and global health status scale and 25 and below for symptom scale.

Affected quality of life: Participants who were scored below 75 for functional and global health status scale and above 25 for symptom scale(17).

\section{Data collection tools}

Data was collected by using a structured questionnaire that was adapted from literature (16-18). The questionnaire was $1^{\text {st }}$ prepared in English and then translated to the Amharic language by experts and, then re-translated back to English by another expert to ensure the uniformity of the instrument. Five percent of the sample size was pre-tested in Haleluia hospital to check the calarity of the questionarie.

\section{Data collection procedure}

Six BSc nurses and two MSc supervisors were used for data collection. One day training was given for clarification of some terms and assessment tools, the aim of the study concerning the need for strict 
confidentiality of respondent's information and time of data collection. Supervisors were closely monitored daily data during data collection.

\section{Data quality control}

A pre-teste was done on $5 \%$ of the total sample size. One full-day training was given for data collectors and supervisors regarding the study, the questionnaire and the data collection procedure. The Collected data were checked every day by supervisors and principal investigators for its completeness. Data was kept in the secured place where no one can access it and confidentiality were ensured by not recording names or any personal identity.

\section{Data processing and analysis}

Data were checked, cleaned and coded before entered to epi-data manager version 4.2. Next data was entered (double entry) into epi-data and transferred into SPSS version 25 for analysis. Descriptive statistics were used to analyze demographic characteristics. Logistic(bivariate and multivariate) regression models were used to evaluate associations between social support, and quality of life at $95 \%$ $\mathrm{Cl}$. Variables found to have a P-value $<0.2$ in the binary logistic regression were entered into multivariate analysis and strength of association was declared at $P$ value $<0.05$.

\section{Ethical consideration}

Ethical clearance was obtained from the institutional review board of Addis Ababa University, College of Health Sciences, School of Nursing and Midwifery. A support letter from the School of Nursing and Midwifery was written to Tikur Anbesa Specialized hospital. Informed written consent was gained from all study participants. Participants were informed about the importance of the study and respondents were reassured that they would be anonymous (unnamed). Then respondents were given a chance to ask anything about the study and were free to refuse or stop at any moment they want if their choice.

\section{Results}

\section{Socio-demographic characteristics of the participants}

A total of 214 participants were included in this study. The mean age was 41.85 and the range of age was from 20 to 80 years. Most of the participants were orthodox 142 (66.4\%) followed by Muslim 41 (19.2\%). Sixty-six (30.8\%) of the participants were illiterate. From the total respondents, 104 (48.6\%) were housewives. Ninety (42.1\%) of the respondents got monthly income $\geq 2000$ ETB (Ethiopian Birr). Among total participants, 155(72.5\%) were diagnosed with breast cancer before 12 months. Among the total participants, $129(60.3 \%)$ of them were received, surgery with chemotherapy treatment (Table 1$)$. 


\section{Social support characteristics of the participants}

Among the total respondents, $175(81.8 \%)$ had someone to listen to them when they need to talk and they got good advice about their problem. The majority of them, $177(82.7 \%)$ got information that helps them to understand a situation and $178(83.2 \%)$ of them had a person to share their most private worries and fears. Among the total participants, $182(84.3 \%)$ had someone to help them when they were confined to bed. Of the respondents, $170(80.1 \%)$ had someone to prepare their meals if they were unable to do it themselves and $173(80.8 \%)$ participants had someone to help with daily activity when they were sick (Table 2).

The social support status of the participants was assessed using a 5-point Likert scale of 19 items. For each item participants who responded some of the time and most of the time were classified as having good social support and participants who scored mean and above the mean (44.17) of the total 19 items were classified having as good social support. Baseds on this, women with breast cancer who had good social support were $124(58 \%)$.

\section{Quality of life of the participants}

Participants scored a global health status scale with a mean $=83.61$ and $S D=20.9$. From EORTC-C30 Functional scales the best score was observed a mean of $75.5(S D=26)$ for social functioning. Whereas, in the QLQ-BR23 functioning scales, the best score was observed for future perspective mean=78 and $S D=33.6)$. Participants also had a low mean score (20) for sexual functioning (Table 3).

To assess the quality of life of the participants, there are three sub scales: - functional scale, symptom scales and global health status scale. Based on this, participants who scored 75 and above for functional and global health status scale and 25 and below for symptom scale classified as not affected quality of life whereas, participants who scored below 75 for functional and global health status scale and above 25 for symptom scales classified as affected quality of life. Among the total participants, $48(22.4 \%)$, $150(70.1 \%)$ and $192(89.7 \%)$ of them had affected QoL, in global health status scale, functional scales and symptom scales respectively. Participants who had not affected QoL were 16 (7.48\%).

\section{Association of variables and social support among female breast cancer patients}

Among the total study participants, $73(34.1 \%)$ of breast cancer patients were college graduated. It was found that participants who were college graduated were more likely to have good social support 3 times than those who were illiterate (AOR=3, 95\%Cl: 1.5, 5.9 COR=3.2). And from total participants, $85(39.7 \%)$ of them had monthly income more than 2000 ETB. It was found that participants who had high monthly 
income were more likely to have good social support by 5.39 times than those who had less monthly income $(\mathrm{AOR}=2.3,95 \% \mathrm{Cl}: 1.2,8.5, \mathrm{COR}=5.39)($ Table S1).

\section{Association of variables and quality of life among female breast cancer patients}

Among the total study participants, 28(13.1\%) of breast cancer patients were illiterate. It was found that participants who were illiterate were more likely to have affected QoL by 3 times than those who were more educated $(\mathrm{AOR}=3,95 \% \mathrm{Cl}$ : 1.3,6.9, $\mathrm{COR}=4.8, \mathrm{p}$-value=0.008). Among the total study participants, $45(21 \%)$ of breast cancer patients had systematic therapy side effects. It was found that participants who had systematic therapy side effects were more likely to have affected QoL by 3.8 times than who had no systemic therapy side effect $(A O R=3.8,95 \% \mathrm{Cl}: 1.1,13, \mathrm{COR}=4$, $\mathrm{p}$-value=0.035). Among the total participants, $45(21 \%)$ of the breast cancer patients had an appetite loss problem. It was found that participants who had a problem of appetite loss were more likely to have affected QoL by 3.5 times than those who had no problem of appetite loss (AOR=3.5, 95\%Cl: 1.02,12COR=4, p-value= 0.047) (Table S2).

\section{Discussion}

This study assessed social support and QoL among female breast cancer patients at TASH. The overall social support mean score was about 44.17 in the current study. This study finding is lower than the study done in Nepal, which showed that the mean score was 85.03(19). The difference might be due to the socioeconomic difference, educational status of and the awareness level of the participants.

The average global health status score of study participants' in this study was about 83.6. This result is consistent with the study done in Nepal which was (82.08)(19). This similarity might be due to the study design and similarityof tools used. However, the current finding is high compared to the study done in Addis Ababa that was (52.5)(17), EORTC reference mean score was (61.8 \pm 24.6$)(20)$ and in South India mean score was (77.93)(21). This difference might be due to the stage of diseases, type of treatment and time difference since diagnosis.

In this study, the role functioning was the lowest $(23.8 \pm 32.80)$ and the highest was observed in social functioning $(75.5 \pm 26)$. The finding is comparable to the study conducted in Ethiopia with a mean score of $74.1 \pm 28.5(17)$. The similarity might be due to the study design, study tool, similarity of study participants and study settings. But, the finding is lower comparing with the EORTC reference value of mean score(77)(20) and study conducted in South India mean score(87.7 \pm 24.6$)(21)$. The difference might be due to educational level differences, study participant age difference, awareness about the disease's consequence and stage of the diseases.

In QLQ-BR23 functioning scales, the highest mean score $(78 \pm 33.6)$ was observed in a future perspective scale. The finding is comparable in the study done in Addis Ababa Ethiopia's mean score(82.1 \pm 30.3$)$ (17). Whereas, the finding is greater than the study conducted in South India's mean score was (72.62 \pm 
33.81) (21). The difference might be due to participants' obtained psychological and social support through informal ways such as family and in a religious institution.

In the QLQ-C30 symptom scales, a higher mean score $(67.8 \pm 22.8)$ was observed in pain. The finding was greater than the study conducted in South India with the mean score of(19.6 \pm 26.64$)(21)$, Ethiopia with the mean score of $(46.0 \pm 31.9)(17)$ and the EORTC reference value mean score $(28.7 \pm 28.7)(20)$. This difference might be due to the availability of anti-pain, the use of ani-pain properly, awareness about the importance of anti-pain medication and their side effect. In QLQ-BR23 symptom scales highest mean score $(55.9 \pm 17.7)$ was observed in systematic therapy side effects. This finding is greater than the study done in South India mean score (13.04 \pm 11.93$)(21)$ and in Addis Ababa Ethiopia mean score (34.6 \pm 29.7)(17). This alteration might be due to the type of treatment, stage of the diseases.

Participants who were college graduated were about 3 times more likely to have good social support than those who were illiterate. This is in agreement with the study done in Italy and in New York $(5,22)$. This similarity might be due to awareness about the importance of social support. Study participants who were illiterate were nearly 3 times more likely to have affected QoL than those who were educated. This finding is supported with a study conducted in Shanghai, China (22) more educated breast cancer patients had improved quality of life. The similarity might be due to awareness about the side effects of treatment and proper management of treatment side effects.

High monthly income in the current study was more likely to have brought a good quality of life. This finding is in agreement with the study done in Shanghai, China(22) high monthly income associated with good quality of life and study done in Addis Ababa(17) those who have reported that they didn't have income, less likely to have a good (unaffected) quality of life. This similarity might be due to can get necessary medication, food, self-care materials and can afford necessary things.

Those who were classified as having affected emotional functioning and role functioning in functional scales were 2.3 times more likely to have affected QoL. This finding was comparable with the study done in Addis Ababa participants who were classified as having unaffected emotional and cognitive functioning were about 2 times more likely to have good QOL(17). This similarity might be due to the similarity of the study design, study tool and study setting area.

Participants who were having a problem of fatigue, nausea and vomiting, appetite loss and financial difficulty in this study were more likely to have affected QoL. Whereas, the study conducted in Ethiopia(17) those who were having fatigue were less likely to have unaffected QoL and those who have no problem with nausea and vomiting, appetite loss and financial difficulties were more likely to have unaffected QoL. This similarity might be due to the stage of the diseases, type of treatment and availability of treatment.

Participants who had poor levels of social support were 2.8 times more likely to have affected the quality of life in the current study. This is supported by the study done in California $(8,23)$ greater social support was related to good QOL after a diagnosis of breast cancer and a study done in Turk(24) good social 
support is the best predictor of quality of life in breast cancer. This similarity might be due to the fact that social support might help to improve the quality of life among patients.

Based on the finding of this study, above half of the total respondents had diverse social networks, the majority of them had good social support and very few of them had not affected quality of life. Education, and monthly income were significantly associated with social support. Education, monthly income, emotional functioning, role functioning, pain, fatigue, financial difficulty, systemic therapy side effect, and social support were significantly associated with QoL.

\section{Limitation of the study}

It hinders the possibilities of assessing for cause and effect associations, the design limits the progressive investigation of social support and quality of life improvements following a series of intervention strategies and it is also possibly subjected to social desirability bias as the study outcome is self-reported.

\section{Recommendations}

Healthcare providers improve social support which may help to improve the quality of life of women with breast cancer and should teach the patients, attendants and other stakeholders about social support to improve the outcome of a disease.

\section{Abbreviations}

EORTC-QLQ-BR

European Organization on Research and Treatment of Cancer, Quality of life, AOR:adjusted odds ratio, COR:crude odds ratio, QOL:quality of life, TASH:Tikure-Anbessa Specialized Hospital, Cl:confidence interval, SD:standard deviation

\section{Declarations}

\section{Consent for publication}

Not applicable.

\section{Availability of data and material}

The data sets used and/or analyzed during the current study are available from the corresponding author on reasonable request.

\section{Competing interests}


The Corresponding author declares that there were no competing interests

\section{Funding}

Addis Ababa University

\section{Acknowledgments}

We would like to express our deepest heartfelt thanks to Addis Ababa University for allowing to conduct this study. Our special thanks go to Tikur Anbessa specialized Hospital staff for their support during the data collection process.

Authors' information

- Rahel Aberaraw is a clinical oncology nurse in the department of oncology, Tikure Anbessa Specialized hospital, Addis Ababa, Ethiopia.

\section{References}

1. Meric F, Bernstam EV, Mirza NQ, Hunt KK, Ames FC, Ross MI, et al. Breast cancer on the world wide web: cross sectional survey of quality of information and popularity of websites. Bmj. 2002;324(7337):577-81.

2. Vorobiof DA, Sitas F, Vorobiof G. Breast cancer incidence in South Africa. Journal of clinical oncology. 2001;19(18; SUPP):125 s-s.

3. Fitzmaurice C, Dicker D, Pain A, Hamavid H, Moradi-Lakeh M, Maclntyre MF, et al. The global burden of cancer 2013. JAMA oncology. 2015;1(4):505-27.

4. Memirie ST, Habtemariam MK, Asefa M, Deressa BT, Abayneh G, Tsegaye B, et al. Estimates of Cancer Incidence in Ethiopia in 2015 Using Population-Based Registry Data. Journal of Global Oncology. 2018;4:1-11.

5. Crookes DM, Shelton RC, Tehranifar P, Aycinena C, Gaffney AO, Koch P, et al. Social networks and social support for healthy eating among Latina breast cancer survivors: Implications for social and behavioral interventions. J Cancer Surviv. 2016;10(2):291-301.

6. Sammarco A, Konecny LM, editors. Quality of life, social support, and uncertainty among Latina and Caucasian breast cancer survivors: a comparative study. Oncology Nursing Forum; 2010.

7. Skeels MM, Unruh KT, Powell C, Pratt W, editors. Catalyzing social support for breast cancer patients. Proceedings of the SIGCHI Conference on Human Factors in Computing Systems; 2010: ACM.

8. Kroenke CH, Kubzansky LD, Schernhammer ES, Holmes MD, Kawachi I. Social networks, social support, and survival after breast cancer diagnosis. Journal of clinical oncology. 2006;24(7):110511. 
9. Pinquart M, Duberstein PR. Associations of social networks with cancer mortality: a meta-analysis. Crit Rev Oncol Hematol. 2010;75(2):122-37.

10. Tadele N. Evaluation of quality of life of adult cancer patients attending Tikur Anbessa specialized referral hospital, Addis Ababa Ethiopia. Ethiopian journal of health sciences. 2015;25(1):53-62.

11. Kroenke CH, Quesenberry C, Kwan ML, Sweeney C, Castillo A, Caan BJ. Social networks, social support, and burden in relationships, and mortality after breast cancer diagnosis in the Life After Breast Cancer Epidemiology (LACE) study. Breast cancer research treatment. 2013;137(1):261-71.

12. Berkman LF, Glass T, Brissette I, Seeman TE. From social integration to health: Durkheim in the new millennium $\rrbracket$. Soc Sci Med. 2000;51(6):843-57.

13. Cohen S, Doyle WJ, Skoner DP, Rabin BS, Gwaltney JM. Social ties and susceptibility to the common cold. Jama. 1997;277(24):1940-4.

14. Woldeamanuel YW, Girma B, Teklu AM. Cancer in Ethiopia. The Lancet Oncology. 2013;14(4):28990.

15. Woldu M, Legese D, Abamecha F, Berha A. The Prevalence of Cancer and its Associated Risk Factors among Patients Visiting Oncology Unit, Tikur Anbessa Specialized Hospital, Addis Ababa-Ethiopia. J Cancer Sci Ther. 2017;9:414-21.

16. Smith TW, Marsden P, Hout M, Kim J. General social surveys. National Opinion Research Center. 2012.

17. CANCER AT TIKUR ANBASSA SPECIALIZED HOSPITAL, ADDIS ABABA, ETHIOPIA Page I. ASSESSING THE QUALITY OF LIFE AMONG PATIENTS WITH BREAST. CANCER AT TIKUR ANBASSA SPECIALIZED HOSPITAL, ADDIS ABABA, ETHIOPIA.

18. Aung MN, Moolphate S, Aung TNN, Katonyoo C, Khamchai S, Wannakrairot P. The social network index and its relation to later-life depression among the elderly aged $\geq 80$ years in Northern Thailand. Clin Interv Aging. 2016;11:1067.

19. Shrestha JS, Shresta A, Spkata A, Sharma R, Shrestha S, Shestha S. Social support, quality of life and mental health status in breast cancer patients. Cancer Rep Rev. 2017;1(2):1-5.

20. Scott N, Fayers P, Aaronson N, Bottomley A, de Graeff A, Groenvold M, et al. EORTC QLQ-C30. Reference values Brussels: EORTC; 2008.

21. Dubashi B, Vidhubala E, Cyriac S, Sagar T. Quality of life among young women with breast cancer: Study from a tertiary cancer institute in south India. Indian journal of cancer. 2010;47(2):142.

22. Spatuzzi R, Vespa A, Lorenzi P, Miccinesi G, Ricciuti M, Cifarelli W, et al. Evaluation of social support, quality of life, and body image in women with breast cancer. Breast Care. 2016;11(1):28-32.

23. Kroenke CH, Kwan ML, Neugut Al, Ergas IJ, Wright JD, Caan BJ, et al. Social networks, social support mechanisms, and quality of life after breast cancer diagnosis. Breast cancer research treatment. 2013;139(2):515-27.

24. Yilmaz MS, PIYAL B, Akdur R. Social support and quality of life in a group of cancer patients (Ankara, Turkey). Turkish journal of medical sciences. 2017;47(3):732-7. 


\section{Tables}

Table 1: Socio-demographic and clinical factor characteristics of the participants at TASH, Addis Ababa, Ethiopia 2019. 


\begin{tabular}{|c|c|c|}
\hline Variable & Frequency $n=214$ & Percent \\
\hline \multicolumn{3}{|l|}{ Age } \\
\hline$<40$ & 106 & 49.5 \\
\hline $40-49$ & 54 & 25.2 \\
\hline $50-59$ & 29 & 13.6 \\
\hline$\geq 60$ & 25 & 11.7 \\
\hline \multicolumn{3}{|l|}{ Religion } \\
\hline Orthodox & 136 & 63.6 \\
\hline Muslim & 41 & 19.1 \\
\hline Protestant & 31 & 14.5 \\
\hline Catholic & 6 & 2.8 \\
\hline \multicolumn{3}{|l|}{ Educational status } \\
\hline Illiterate & 66 & 30.8 \\
\hline Grade1-8 & 38 & 17.8 \\
\hline Grade 9-12 & 64 & 29.9 \\
\hline College graduated & 46 & 21.5 \\
\hline \multicolumn{3}{|l|}{ Occupation } \\
\hline Housewife & 104 & 48.6 \\
\hline Governmental & 44 & 20.6 \\
\hline Private & 34 & 15.8 \\
\hline Student & 3 & 1.4 \\
\hline Pension & 29 & 13.6 \\
\hline \multicolumn{3}{|l|}{ Monthly income in ETB } \\
\hline$<500$ & 67 & 31.3 \\
\hline $501-1000$ & 27 & 12.6 \\
\hline $1001-1500$ & 20 & 9.3 \\
\hline $1501-2000$ & 10 & 4.7 \\
\hline$\geq 2000$ & 90 & 42.1 \\
\hline \multicolumn{3}{|l|}{ Smoking } \\
\hline Current & 9 & 4.2 \\
\hline Past & 3 & 1.4 \\
\hline Never & 202 & 94.4 \\
\hline \multicolumn{3}{|l|}{ Alcohol intake } \\
\hline Current & 2 & 0.9 \\
\hline Past & 9 & 4.2 \\
\hline Never & 203 & 94.9 \\
\hline \multicolumn{3}{|l|}{ Physical activity } \\
\hline$<3$ & 24 & 11.2 \\
\hline $3-17$ & 172 & 80.4 \\
\hline$\geq 18$ & 18 & 8.4 \\
\hline \multicolumn{3}{|l|}{ Type of treatment } \\
\hline Chemotherapy & 51 & 23.8 \\
\hline Surgery and chemotherapy & 148 & 69.2 \\
\hline Surgery, chemotherapy and radiation therapy & 15 & 7 \\
\hline \multicolumn{3}{|l|}{ Stage of diseases } \\
\hline Stage 1 & 75 & 35 \\
\hline Stage 2 & 24 & 11.2 \\
\hline Stage 3 & 20 & 9.3 \\
\hline Stage 4 & 54 & 25.4 \\
\hline Recurrence & 41 & 19.1 \\
\hline \multicolumn{3}{|l|}{ Time since diagnosis } \\
\hline$<12$ month & 155 & 72.5 \\
\hline 13-24 month & 14 & 6.5 \\
\hline
\end{tabular}




\begin{tabular}{lll} 
25-34 month & 6 & 2.8 \\
$35-59$ month & 22 & 10.3 \\
$\geq 60$ month & 17 & 7.9 \\
\hline
\end{tabular}

Table 2: Social support characteristics among female breast cancer patients at TASH, Addis Ababa, Ethiopia 2019.

\begin{tabular}{|c|c|c|c|c|c|}
\hline Items & $\begin{array}{l}\text { None of the time } n \\
(\%)\end{array}$ & $\begin{array}{l}\text { A little of the time } n \\
(\%)\end{array}$ & $\begin{array}{l}\text { Some of the time } n \\
(\%)\end{array}$ & $\begin{array}{l}\text { Most of the time } n \\
(\%)\end{array}$ & $\begin{array}{l}\text { All of the time } n \\
(\%)\end{array}$ \\
\hline \multicolumn{6}{|l|}{ Availability of someone to: } \\
\hline Listen to you & $3(1.4)$ & $36(16.8)$ & $50(23.8)$ & $49(22.9)$ & $76(35.1)$ \\
\hline Give you good advice & $5(2.3)$ & $34(15.9)$ & $56(26.2)$ & $47(22)$ & $72(33.6)$ \\
\hline Give you information & $5(2.3)$ & $32(15)$ & $58(27.1)$ & $56(26.2)$ & $63(29.4)$ \\
\hline $\begin{array}{l}\text { Give advice you really } \\
\text { want }\end{array}$ & $5(2.3)$ & $37(17.3)$ & $54(25.2)$ & $56(26.2)$ & $62(29)$ \\
\hline Share worries with & $4(1.9)$ & $32(15)$ & $56(26.2)$ & $58(27.1)$ & 64(29.9) \\
\hline Turn to for suggestions & $4(1.9)$ & $33(15.4)$ & $59(27.6)$ & $60(28)$ & $58(27.1)$ \\
\hline $\begin{array}{l}\text { Understand } \quad \text { your } \\
\text { problems }\end{array}$ & $2(0.9)$ & $34(15.9)$ & $55(25.7)$ & 64(29.9) & $59(27.6)$ \\
\hline Confide in & $4(1.9)$ & $27(12.6)$ & $59(27.6)$ & 67(31.3) & $57(26.6)$ \\
\hline Help if confined to bed & $3(1.4)$ & $29(13.6)$ & $58(27.1)$ & $69(32.2)$ & $55(25.7)$ \\
\hline Take to doctor & $5(2.3)$ & $33(15.4)$ & $58(27.1)$ & $61(28.5)$ & $57(26.6)$ \\
\hline Prepare meals & $5(2.3)$ & $39(18.2)$ & $49(22.6)$ & $69(32.6)$ & $52(24.3)$ \\
\hline Help with daily tasks & $5(2.3)$ & $36(16.8)$ & $61(28.5)$ & $61(28.5)$ & $51(23.8)$ \\
\hline Love you & $10(4.7)$ & $36(16.8)$ & $58(27.1)$ & $63(29.4)$ & $47(22)$ \\
\hline Hug you & $9(4.2)$ & $37(17.3)$ & $63(29.4)$ & $59(27.6)$ & $46(21.5)$ \\
\hline Show love and affection & $11(5.1)$ & $36(16.8)$ & $67(31.3)$ & $55(25.7)$ & $45(21)$ \\
\hline With for relaxation & $16(7.5)$ & $38(17.8)$ & $61(28.5)$ & $54(25.2)$ & $45(21)$ \\
\hline $\begin{array}{l}\text { Do something enjoyable } \\
\text { with }\end{array}$ & $17(7.9)$ & $37(17.3)$ & $64(29.9)$ & $52(24.3)$ & $44(20.6)$ \\
\hline Have good time with & $16(7.5)$ & $40(18.7)$ & $67(31.3)$ & $49(22.9)$ & $42(19.6)$ \\
\hline Mind off things & $16(7.5)$ & $45(21)$ & $60(28)$ & $50(23.4)$ & $43(20.1)$ \\
\hline
\end{tabular}


Table 3: Quality of life characteristics of female breast cancer patients at TASH, Addis Ababa, Ethiopia 2019.

\begin{tabular}{ll}
\hline Scales & Mean \pm SD \\
\hline Global health status/QOL & $83.61 \pm 20.9$ \\
$\quad$ EORTC QLQ-C30 functional scale & \\
Physical functioning & $60 \pm 21.8$ \\
Role functioning & $23.8 \pm 32.8$ \\
Emotional functioning & $59.1 \pm 38.7$ \\
Cognitive functioning & $72.8 \pm 28.2$ \\
Social functioning & $75.5 \pm 26$ \\
EORTC QLQ-C30 symptom scale & \\
Fatigue & $64.1 \pm 23.5$ \\
Nausea and vomiting & $30.7 \pm 28$ \\
Pain & $67.8 \pm 22.8$ \\
Dyspnea & $41.3 \pm 31.5$ \\
Insomnia & $47.2 \pm 35.8$ \\
Appetite loss & $59.3 \pm 32.8$ \\
Constipation & $14.8 \pm 26$ \\
Diarrhea & $14 \pm 29.3$ \\
Financial difficulty & $63 \pm 43$ \\
EORTC QLQ-BR23 functional scale & \\
Body image & $76.9 \pm 33.5$ \\
Sexual functioning & $20.1 \pm 20$ \\
Sexual enjoyment & $35.6 \pm 25.4$ \\
Future perspective & $78 \pm 33.6$ \\
EORTC QLQ-BR23 symptom scale & \\
Systemic therapy side effect & $55.9 \pm 17.7$ \\
Breast symptoms & $20.3 \pm 21.6$ \\
Arm symptoms & $20.4 \pm 22.3$ \\
Upset by hair loss & $15.6 \pm 29$ \\
\hline
\end{tabular}

\section{Supplementary Files}

This is a list of supplementary files associated with this preprint. Click to download.

- supplement5.docx 